\title{
Integrating Heat Repulsion and Strength Evaluation of Cost-Effective GLP Concrete Redeeming the Cement Proportions Utilizing Thermocouples
}

\author{
Mir Masood Shah * \\ Civil Engineering Department, \\ Sarhad University of Science and Information \\ Technology, Peshawar, Pakistan \\ Ali Ahmad Jibran \\ Civil Engineering Department, \\ Sarhad University of Science and Information \\ Technology, Peshawar, Pakistan \\ Hamza Kundi \\ Electronics Engineering Department, \\ Sarhad University of Science and Information \\ Technology,Peshawar, Pakistan
}

\author{
Muzammil Yaqoob \\ Civil Engineering Department, \\ Sarhad University of Science and Information \\ Technology, Peshawar, Pakistan \\ Arif Rashid \\ Civil Engineering Department, \\ CECOS University, Peshawar, Pakistan
Mateeullah
Civil Engineering Department, Sarhad University of Science and Information Technology, Peshawar, Pakistan

\author{
Muhammad Siyab Khan \\ Civil Engineering Department, \\ Sarhad University of Science and Information \\ Technology, Peshawar, Pakistan
}

\begin{abstract}
Waste glass is risky in our local environment to be dumped as garbage causing harmful problems in the reaction of alkali and silica. The concept was proposed to take advantage of waste glass crushing it into the powder for merging into concrete as a binding material for producing low-cost concrete with imparting effective thermal insulation property. Novelty in this investigation is to introduce an innovative and cheap electronic tool with precision and accuracy called thermocouple which was locally designed by an electronic engineer to calculate the rate of transfer of heat through glass powder (GLP) concrete cylinder. This tool was embedded in the fresh concrete connected with a digital thermometer which was later on tested in an oven after being hardened. Cement was somewhat replaced by glass powder (GLP) in casting cylinders. Many cylinders were cast with regular concrete and investigated for strengths, thermal insulation and other properties and compared with concrete using glass powder (GLP) as a partial interchange of cement in different proportions such as $5,10,15,20$, and $25 \%$. The results were later compared to analyse the behaviour of GLP concrete where the slightly negative strength differences were noted compared to the controlled concrete. At the same time, the cost of concrete was lowered for use in the non-load carrying members as well as in the construction of temporary buildings in the rural areas. The important point here to mention is that GLP improved the thermal insulation property of the concrete in an effective, accurate and mostly importantly low-cost locally made tool providing a cool pleasant environment to the occupants especially in the counties where the temperature exceeds $40^{\circ} \mathrm{C}$ in the summer.
\end{abstract}

Keywords: Cement, Concrete, Glass powder (GLP), Pozzolana, Thermocouple, Thermal insulation

\footnotetext{
${ }^{*}$ Correspondence concerning this article should be addressed to Mir Masood Shah, Civil Engineering Department, Sarhad University of Science and Information Technology, Peshawar, Pakistan. E-mail: uols.marwat@gmail.com

(c) 2020 The Author(s). Published by KKG Publications. This is an Open Access article distributed under a Creative Commons AttributionNonCommercial-NoDerivatives 4.0 International License.
} 
Received: 09 April 2020; Accepted: 19 June 2020; Published: 29 August 2020

\section{INTRODUCTION}

Bond in reinforced concrete $(\mathrm{RC})$ denotes the resistance of neighboring cement counters to pulling from strengthening bars. Friction is caused by deformations of the bars, or ribs that slide along the concrete, and mechanical interlocking is a bearing force caused by bearing ribs against concrete. If the bond strength is insufficient, the reinforcing tape slip occurs which leads to the destruction of the composite work. In RC members, sudden loss of the bond between rebar and concrete in the fixing areas causes brittle failure of the bond [1].

The past reported studies indicated that the mechanism of resistance in $\mathrm{RC}$ members is recognized in the concrete of normal strength [2]. However, information on the impact of binding materials on the bond strength of concrete and embedded reinforcement is not available. This research will help to find the effect of using pozzolanic materials on the bond strength of reinforcements embedded in concrete. Currently, many researchers have the view to use alternatives to Portland cement, by the usage of waste materials and products of industrial processes. These include granular blast furnace slag and powder fly ash [3]. The use of these materials as binders partially substituting the cement is done at the time of hydration. It is also known to be used as filler. The glass is a large group compound like triplex soda-lime silicate glass, paper silicate glass, and di-alkali silicate glass. The microstructure attains benefit from crushed waste glass, which partially replaces the cement. It also confirms the additional stability of the fixative material [4]. When ground glass waste replaces partially cement, it results in the production of a denser (less porous) and much homogenous structure. It gives additional stability and durability of reinforced material making it resistant to absorption of moisture. The stability of cement also increases with few amount of interchange of cement with crushed glass waste [5]. The potentially harmful interactions have been observed between cement hydrates and reactive aggregates, which can be reduced using mixed-colour waste glass [6]. The waste glass must be crushed as fine as cement and used as a substitution of the total of $20 \%$ of cement in concrete. It helps to enhance the water retention properties, stability, and mechanical performance of concrete [7]. These modifications are made from the useful chemical reactions of crushed glass waste with cement hydrate, resulting in producing chemically durable products hav- ing the capability of purifying the pore system in concrete. It is beneficial for the environment, energy, and cost-efficient, and cheap. In the construction industry, the widely used building material is concrete across the globe. The concrete is made by homogenously mixing cement, fine and coarse aggregates, and water. The composition and cement material quality govern the quality of the concrete. Cement is a finely ground substance that does not develop independently from anyone else but is formed as a result of the binding property of hydration [8]. Normal concrete cement is produced by maximizing cement concrete. Its strength ranges from $10 \mathrm{MPa}$ to $40 \mathrm{MPa}$ with the time required for the initial setting being 30-90 minutes, mainly relying upon the properties of the cement. The unit weight of lightweight concrete cement is not equal to the weight of concrete made with basic anchors. The unit weight usually turns from 240 $\mathrm{kg} / \mathrm{m}^{3}$ to $1850 \mathrm{~kg} / \mathrm{m}^{3}$. The lightweight quality is $7 \mathrm{MPa}$ to $40 \mathrm{MPa}$ [9]. Air-filled concrete is an amazing innovation in concrete innovation. It is delivered by mixing an air-drying agent with typical cement. The quality of this type of concrete is lower than that of ordinary cement [10]. High strength concrete cement is delivered by the amazing aggregate selection, low weight/weight ratio, and mixture mixing for concrete. The quality of this is about 6000 psi. This uncommon type of quality concrete can range from 10,000 to 15,000 psi. This means that it is of high quality. What's more, it's also powerful [11]. Glass is amorphous (amorphous) and is essentially a super cooled liquid rather than a solid. It can be manufactured with exceptional homogeneity in different shapes and sizes [12]. The glass can be made from small fibres to metric-sized pieces. It consists primarily of sand, soda ash, limestone, and other additives. These additives include lead, alumina, iron, cobalt, and chromium [13]. The finely crushed glass is used as a combination in the construction of roads and building as an additive. To make a glass, a mixture of silica, soda ash, and $\mathrm{CaCO}_{3}$ is heated at high temperatures subsequently cooled to solidify avoiding any crystallization in form of transparent material [14]. The glass is used to make a variety of things used in human consumption including glassware, mirrors, windows, tubes, etc. As the production of glass is increasing day by day, the wasted glass is also increasing and adding to pollution [15]. It is not biodegradables hence not eco-friendly so dumping in landfill sites [16]. It is also a growing environmental 
concern as dumping such wasted glass is a big problem for the country. This project is made to utilize the wasted glass in concrete to use it and give additional properties to the building material [17].

\section{A. Objectives of the Study}

Following are the objectives of this investigation.

- To study the development of strength in concrete with different doses of glass powder.

- To study the effect on compressive, tensile, and bending strength using different doses of glass powder treatment under 7,14 , and 28 days.

- To make a comparison of the results of GLP containing concrete with controlled concrete.

- Awareness of civil engineers about the advantages of the new concrete mix.

\section{MATERIALS AND METHODS}

Glass waste is collected from Kohat, Pakistan and is crushed in the PCSIR Peshawar, Pakistan laboratory. Concrete is partially replaced by its weight with glass powder in different proportions, for example, 5\% 10\%, $15 \%, 20 \%$, and $25 \%$. Various research centres were visited to determine the compression test of concrete. Portland cement and cement are mixed with glass powder at different rates. With these results, the control mix, using glass powder and quarry dust replaced as cement and fine aggregate separately, is intended for the cylinder. 18 cylinders were cast in this investigation. At the end of the performance period 7, 14, and 28 days, each cylinder is tried for compression and prisms for flexure.

\section{A. Cement}

The type of cement used in this research is OPC cement imported and made in Pakistan. The main motivation for utilizing Ordinary Portland Cement (Type I) in this study is that it is undoubtedly the most widely used cement and is very proper for use in general concrete construction when there is no contact with sulphate in soil or groundwater.

\section{B. Aggregates}

Relevant tests were done to determine the properties of the aggregates that were intended to be used in this research. Then, corrective actions were taken before proceeding to the mixing consistency. In general, aggregates should be solid and durable, free from unwanted filths, and chemically stable. Porous soft rocks can limit strength and erosion resistance; they may also separate during mixing and negatively affect workability by increasing the total quantity of fines. The aggregate also needs to get rid of impurities: silt, clay, dirt, or organic matter. If these materials cover aggregate surfaces, they will separate aggregate units from the surrounding concrete, resulting in a lower strength. Silt, clay, and extrafine materials will increase the water requirement of the concrete, and the organic matter may hinder the hydration of the cement. To fit suitable concrete mixes, some characteristics of aggregates must be known i.e. shape, texture, moisture content, volume gradation, unit volume weight, and specific gravity.

\section{Water}

Water quality plays an important role in concrete production. Contaminations in the water may restrict the fixation of cement which unfavourably affects the effectiveness of concrete or root to the discoloration of its surface, and may also lead to rusting of the reinforcement [18]. Due to these reasons, the appropriateness of water for mixing and processing purposes must be measured. In this paper, tap water supplied by the Addis Ababa Water and Wastewater Authority at room temperature was used in all mixtures.

\section{Glass powder (GLP)}

The glass powder is a non-metallic waste for industries with no hazardous properties. It is an ideal candidate for mixing in concrete which brings less reduction in its properties which are related to strength [19]. The main aim of the study work is to determine the optimal substitution ratios that can be used appropriately under our local environment and on ground conditions.

It has been examined that the benefits of using GLP can be significant as it reduces thermal cracking caused by the heat of hydration of cement and can advance stability to attacking sulphate and acidic water, resulting in increased concrete performance. Optimum replacement of cement with glass powder gave high strength, permeability, and high-pressure resistance.

Investigation of the effect of GLP in concrete under numerous properties such as permeability, workability, the heat of hydration, toughness, bleeding, sensitivity to curing tensile strength and acid resistance and bending strength, etc. decided that the strength of the 28 days of concrete with glass gives a higher compressive strength compared to other materials such as silica fume. With the addition of GLP, higher compressive strength can be achieved early on, and also very higher flexural strength can be achieved after 28 days by using appropriate concrete mix design. 


\section{E. Selection of Concrete mix Proportions (Mix Design)}

The selection of mixing proportions is an activity of selecting the appropriate components for concrete and evaluating their relative amounts with the production component as economic so that you can select the minimum characteristics, in particular strength, durability, and desired consistency. The important thing to achieve solid and durable concrete is the precise proportioning and mixing of the components. A concrete mixture that does not have sufficient cement paste to the spaces thoroughly between the aggregate will be hard to apply and will produce irregular, honeycomb surfaces and porous concrete. The mixture that contains an excessive amount of cement putty will be convenient to apply and will make an even surface; However, the subsequent concrete will likely shrink more and be wasteful. The accurately designed concrete mix will own the specified workability for the new concrete and the essential durability and strength for the hard-edged concrete.

The chemistry of Portland cement comes in the presence of water. Cement and water form a stick that covers every part of the stone and sand. Through a chem- ical reaction called hydration, the cement paste hardens and gains strength. The smoothness of concrete is determined by the degree of paste. Thus, the effectiveness of the paste depends on the ratio of water to cement. Quality concrete is created by lowering the water-cement ratio around what is possible without sacrificing the workability of fresh concrete. In general, using less water results in high-quality concrete provided that the concrete is properly set and cured and meets any required durability requirements.

\section{F. Batching of Materials}

The surface saturated dry aggregates were useful for the concrete mixes under investigation. Cement and aggregates were collected by weight while water was collected in batches by volume. Most of the replacements for the coarse aggregate have been made on a volume basis. To develop the necessary volume of concrete to be produced, the total amount of test samples must be primarily determined. Hence, the samples required were as follows: 18 cylinder samples for compressive strength test $=0.107 \mathrm{~m}$

TABLE 1

A SHORT SUMMARY OF APPEARANCE-DEPENDENT REGRESSION METHODS FOR GAZE CALCULATION

\begin{tabular}{|c|c|c|c|c|c|c|}
\hline Sr. \# & & \multicolumn{2}{|c|}{ GLP percentage (\%) } & \multicolumn{3}{|c|}{ Mix proportion of concrete $(\mathrm{kg})$} \\
\hline & & Cement $(\mathrm{Kg})$ & Glass (Gram) & $\mathrm{FA}(\mathrm{Kg})$ & $\mathrm{CA}(\mathrm{Kg})$ & Water (Litre) \\
\hline 1 & $5 \%$ & 7.695 & 135 & 10.20 & 21.3 & 3.6 \\
\hline 2 & $10 \%$ & 7.290 & 270 & 10.20 & 21.3 & 3.6 \\
\hline 3 & $15 \%$ & 6.885 & 405 & 10.20 & 21.3 & 3.6 \\
\hline 4 & $20 \%$ & 6.480 & 540 & 10.20 & 21.3 & 3.6 \\
\hline 5 & $25 \%$ & 6.075 & 675 & 10.20 & 21.3 & 3.6 \\
\hline 6 & Normal & 2.7 & & 3.400 & 7.10 & 3.6 \\
\hline
\end{tabular}

\section{G. Sample preparation}

The mixture components must be properly mixed to yield fresh concrete in which the outer lining of wholly aggregate particles are covered with a paste of cement and which can be consistent over a wide range and thus possess uniform properties. Accurate mixing is necessary for the complete mixing of the materials required to produce homogeneous and uniform concrete. Also, extra care is needed to provide during the casting of the specimens and proper ratios of the GLP.

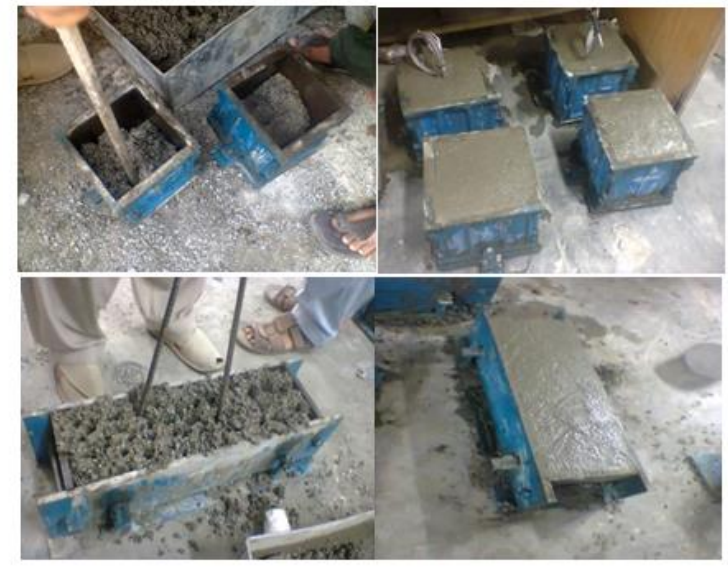

Fig. 1. Moulding of the Cubes and Prisms in the Investigation 
This type of mixing has a significant benefit as defined along with additional forms specifically for this type of research work. Pan mixers offer the opportunity of monitoring the included concrete and thus altering the mix in various cases. It is especially effective with hard and cohesive mixtures. It is also suitable for mixing very small amounts of concrete and is therefore used mostly in the laboratory.

\section{RESULTS AND DISCUSSION}

Following are the results of the tests performed on the different materials being used in this investigation in the laboratory of Sarhad University of Science and Information Technology, Peshawar, Pakistan.

\section{A. Chemical composition analysis of glass powder}

Following are the calculated values in the table as under:
TABLE 2

CHEMICAL COMPOSITION ANALYSIS OF GLP

\begin{tabular}{lll} 
Sr. No. & Chemical & Percentage $(\%)$ \\
\hline 1 & Slice $(\mathrm{SiO} 2)$ & $72.5 \%$ \\
2 & Alumina $(\mathrm{Al} 2 \mathrm{O} 3)$ & $1.06 \%$ \\
3 & Lime $(\mathrm{CaO})$ & $0.8 \%$ \\
4 & Iron Oxide $(\mathrm{Fe} 2 \mathrm{O} 3)$ & $0.3 \%$ \\
5 & Magnesia $(\mathrm{MgO})$ & $4.1 \%$ \\
\hline
\end{tabular}

\section{B. Slump test}

The concrete mix must be made of the correct quantity of cement, aggregate, and water to make the concrete workable for rapid compaction and stabilization and a permanently strong performance in resisting stresses after hardening. If the mix is excessively dry, it will likely be compacted too hard and if it is much wet, the concrete will possibly be weak.

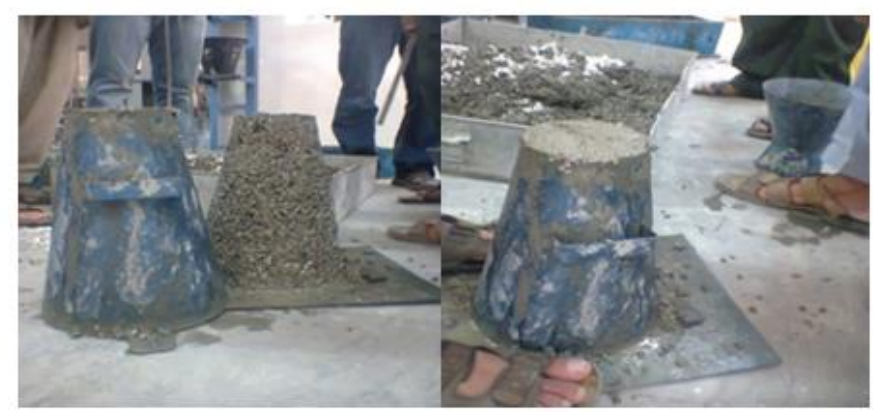

Fig. 2. Slump Test Performance in the Lab

TABLE 3

SLUMP TEST OF CONCRETE

\begin{tabular}{lllll} 
Sr. No. & Glass powder percentage $(\%)$ & Types of concrete & Slump value $(\mathrm{mm})$ & Slump value (inches) \\
\hline 1 & - & Normal Concrete & 25.4 & 1 \\
2 & $5 \%$ & GLP concrete & 25.4 & 1 \\
3 & $10 \%$ & GLP concrete & 33.02 & 1.30 \\
4 & $15 \%$ & GLP concrete & 36.83 & 1.46 \\
5 & $20 \%$ & GLP concrete & 38.1 & 1.51 \\
6 & $25 \%$ & GLP concrete & 39.116 & 1.54 \\
\hline
\end{tabular}

\section{Compressive strength}

The sample of concrete with diverse percentages of glass powder as alternative cement was tested for 7, 14, and 28 days for compressive strength. The replaced amount was $5,10,15,20$, and 25\%. 3 samples were investigated for each alternative and the average of these 3 samples was taken as the compressive strength of con- crete. The mixing ratio is $1: 1.5: 3$. The concrete drum was tested with different proportions of glass powder for 7, 14, and 28 days. For each test, 3 cylinders were investigated and the final result was reserved as an average of these 3 cylinders. In this paper, the mixing ratio was 1:1.5:3. The results of all the samples tested are shown in the following table. 
TABLE 4

COMPRESSIVE STRENGTH OF CONCRETE

\begin{tabular}{llllllllll}
\hline S.\# & Glass percentage (\%) & \multicolumn{4}{c}{ Concrete Strength (Psi) } & \multicolumn{4}{c}{ Mix proportion of concrete (kg) } \\
\cline { 3 - 9 } & & 7 day & 14day & 28day & Cement (Kg) & Glass (Gram) & FA (Kg) & CA (Kg) & Water (Litre) \\
\cline { 3 - 9 } 1 & $5 \%$ & 1402 & 1625 & 2230 & 7.695 & 135 & 10.20 & 21.3 & 3.6 \\
2 & $10 \%$ & 1190 & 1683 & 1818 & 7.290 & 270 & 10.20 & 21.3 & 3.6 \\
3 & $15 \%$ & 508 & 1377 & 1599 & 6.885 & 405 & 10.20 & 21.3 & 3.6 \\
4 & $20 \%$ & 1660 & 1827 & 2145 & 6.480 & 540 & 10.20 & 21.3 & 3.6 \\
5 & $25 \%$ & 1200 & 1370 & 1886 & 6.075 & 675 & 10.20 & 21.3 & 3.6 \\
6 & Normal & 1576 & 2106 & 2237 & 2.7 & & 3.400 & 7.10 & 3.6 \\
\hline
\end{tabular}

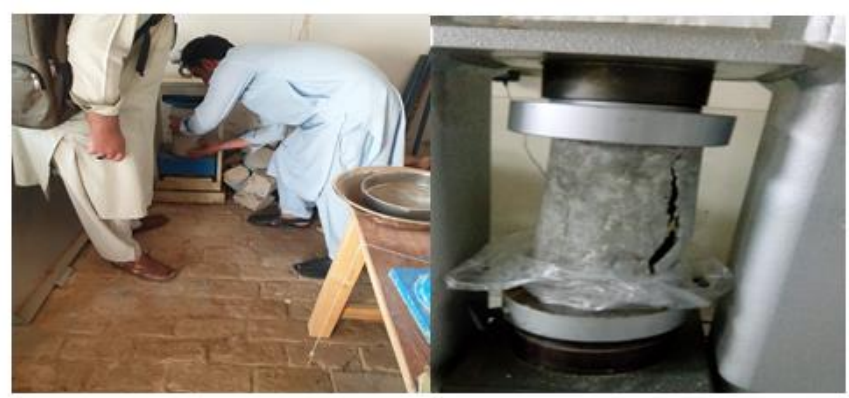

Fig. 3. Compressive Strength Test Performance in the Lab

\begin{tabular}{|c|c|c|c|c|c|c|c|}
\hline \multirow{5}{*}{ 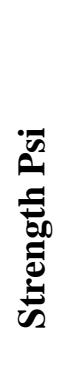 } & \multicolumn{7}{|c|}{$\begin{array}{c}\text { Compressive Strength of } \\
\text { GLP Concrete }\end{array}$} \\
\hline & 5000 & No... & $5 \%$ & $10 \%$ & $15 \%$ & $20 \%$ & $25 \%$ \\
\hline & 7 day & 1576 & 1402 & 1190 & 509 & 1660 & 1201 \\
\hline & -14day & 2107 & 1625 & 1683 & 1378 & 1827 & 1370 \\
\hline & -28day & 2237 & 2230 & 1818 & 1599 & 2146 & 1886 \\
\hline
\end{tabular}

Fig. 4. Compressive Strength Test A Graphical Representation

D. Flexure Strength

Following are the results of flexure strength of normal concrete and GLP concrete performed on the prims cast as shown in figure 5. The casting of the prisms is shown in figure 5 .

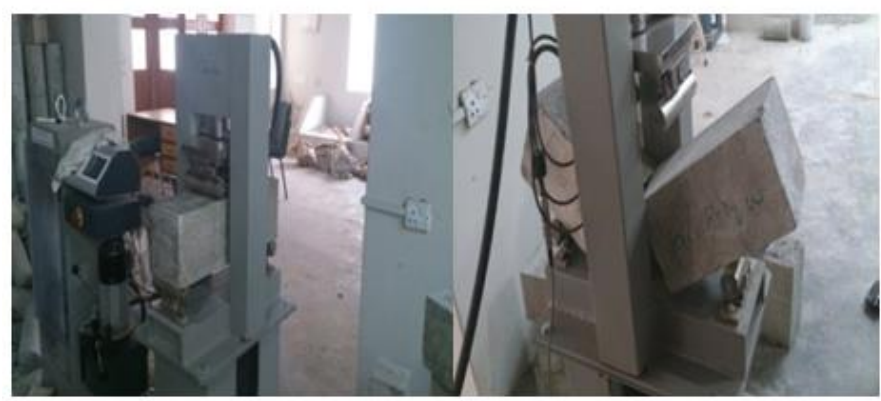

Fig. 5. Flexural Strength Test on Prisms 
TABLE 5

VARIATION OF FLEXURAL STRENGTH WITH THE INCREASE IN GLP CONTENT

\begin{tabular}{llll}
\hline GLP\% & 1st Sample (MPa) & 2nd Sample (MPa) & Average (MPa) \\
\hline 0 & 6.37 & 6.43 & 6.40 \\
10 & 5.13 & 5.19 & 5.16 \\
20 & 4.50 & 4.59 & 4.545 \\
30 & 4.30 & 4.44 & 4.37 \\
40 & 4.21 & 4.09 & 4.15 \\
\hline
\end{tabular}

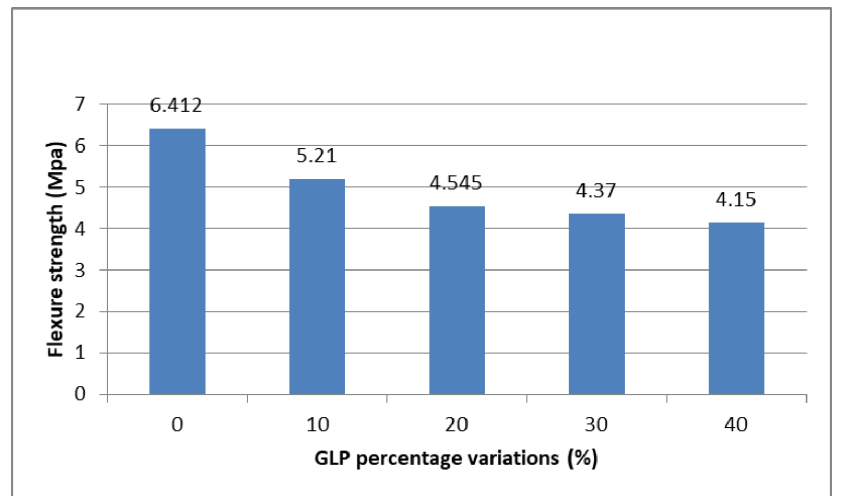

Fig. 6. Flexure Strength Variations Against GLP Contents

\section{E. The density of GLP concrete}

Mass per unit volume is known as density. In this investigation, density was also determined according to the ASTM method and the following are the results of the density of normal and GLP concrete as shown in table and figure as under:

TABLE 6

VARIATION OF DENSITY WITH INCREASE IN GLP CONTENTS

\begin{tabular}{lllllll}
\hline GLP contents (\%) & 0 & 5 & 10 & 15 & 20 & 25 \\
\hline Density $(\mathrm{Kg} / \mathrm{m} 3)$ & 2387.85 & 2104.32 & 1911.61 & 1844.12 & 1691.95 & 1511.21 \\
\hline
\end{tabular}

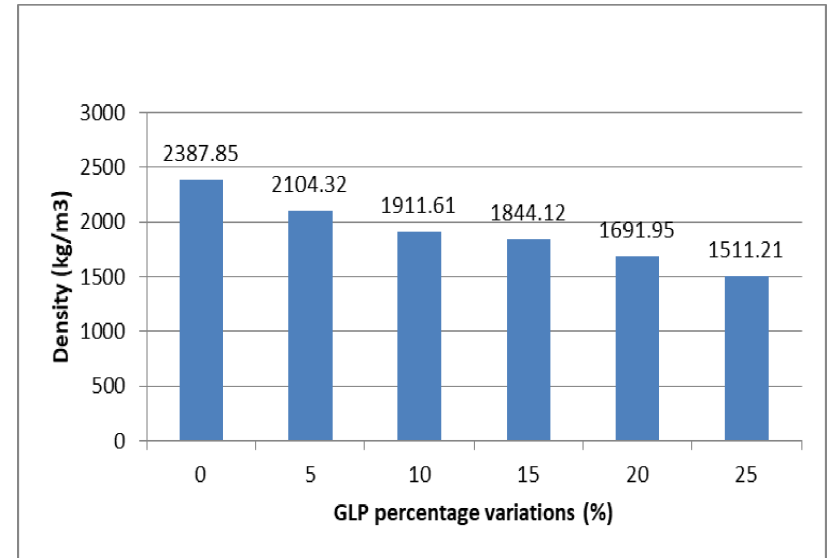

Fig. 7. Density Variations Against GLP Contents

\section{F. Thermal insulation}

The inspiration behind this investigation is to identify the connection between GLP and heat resistance. The device used in this assessment for the assurance of the thermal insulation of concrete cubes is known as Thermo Couple as shown in figure 7 . The recent studies have shown the use of thermocouples in concrete to determine the effect of temperature on the performance of high performance concrete [20]. 


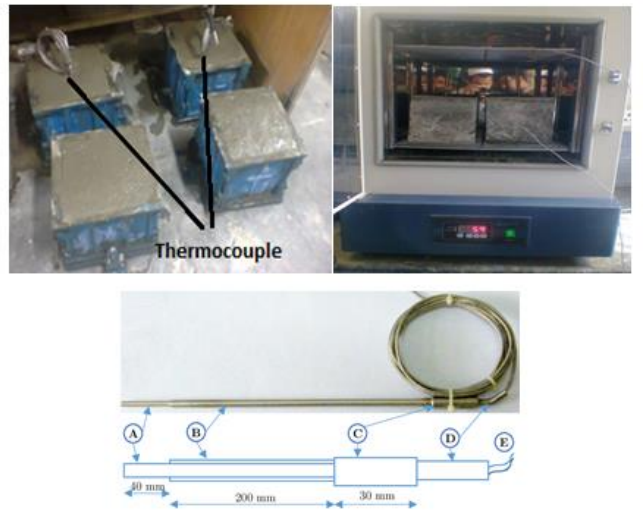

Fig. 8. Thermal Insulation Inspection Performance on GLP Concrete Using J Type Thermocouple

TABLE 7

THERMAL INSULATION PROPERTY INSPECTION OF GLP CONCRETE CUBES

\begin{tabular}{llll}
\hline Percentage (\%) & Time to reach $60^{\circ} \mathrm{C}$ (Hours) & Time to reach $60^{\circ} \mathrm{C}$ (Minutes) & Time Difference (minutes) \\
\hline 0 & 6h $22 \mathrm{~m}=6.30$ & 382 & - \\
5 & $7 \mathrm{~h} 10 \mathrm{~m}=7.07$ & 430 & $(430-382)=48$ \\
10 & 8h $15 \mathrm{~m}=8.10$ & 495 & $(495-430)=65$ \\
15 & $9 \mathrm{~h} 22 \mathrm{~m}=9.38$ & 562 & $(562-495)=67$ \\
20 & $10 \mathrm{~h} 36 \mathrm{~m}=10.60$ & 636 & $(636-562)=74$ \\
25 & $11 \mathrm{~h} 11 \mathrm{~min}=11.21$ & 671 & $(671-636)=35$ \\
\hline
\end{tabular}

Based on the results, it has been concluded that the strength factors have been compromised with appreciable values not less than satisfactory. Similarly, other properties like density etc. are maintained after adding the admixture replacing the cement contents. The property of heat insulation which was the purpose of study was achieved defining the big gap of the heat resistance between the controlled and GLP concrete sample. This research can be proved very effective in modern construction era especially in the developing countries where shortage of energy is a main cause of developmental hurdles provided that the logical and scientific analysis of findings of this study made a huge contribution to the modern research [21, 22].

\section{CONCLUSION}

Based on the experimental study of the use of glass powder as a fractional substitute for cement, the under giving conclusions were achieved from the study.

- Use of glass powder in concrete as a fractional substitute for cement upsurges the call for mixing water to normal workability.

- Glass powder can be utilized efficiently and competently as a fractional substitute for cement in concrete keeping in mind the gravity of concrete.

- Effect of using glass powder in concrete on the concrete compressive strength is quite positive as causing lesser deficiency by increasing GLP content.

- Observations were done from the investigational work that the flexural strength was also not much affected throughout the different percentages of GLP contents used and giving satisfactory strength for any non-load carrying member or temporary buildings.

- It is recommended to use GLP in concrete up to $25 \%$ which gives maximum thermal insulation.

\section{A. Limitations}

Utilizing GLP replacing specific percentages of cement can increase the chemical, mechanical and physical properties of concrete. Usage of waste glass as sustainable material in concrete alternative to the dumping of the waste GLP is reliable. It also decreases the ingestion of natural resources. By consuming waste GLP, manufacturing of cement can be reduced along with the cost of cement production can be reduced. Heat resisting property of the concrete can be achieved effectively.

- To manage the environmental contamination.

- To yield economical concrete.

- Low-cost and cost-effective alternate to landfills, incinerator 


\section{ACKNOWLEDGMENT}

Sincere thanks to all my associates for their kindness and moral support during my project. Thanks for the companionship and memories. My inmost thanks go to my beloved parents. In the end, I acknowledge the amenities of all those personalities who directly or indirectly helped me to finish this investigation work. Thank you very much!

\section{REFERENCES}

[1] S. Pujol, "Bond between deformed bars and concrete," in Principles of Reinforced Concrete Design. Boca Raton, FL: CRC Press, 2014.

[2] M. E. Kaminska, "High-strength concrete and steel interaction in rc members," Cement and Concrete Composites, vol. 24, no. 2, pp. 281-295, 2002. doi: https://doi.org/10.1016/S0958-9465(01)00011-7

[3] A. Castel and S. J. Foster, "Bond strength between blended slag and class f fly ash geopolymer concrete with steel reinforcement," Cement and Concrete Research, vol. 72, pp. 48-53, 2015. doi: https: //doi.org/10.1016/j.cemconres.2015.02.016

[4] BSI. (2021) Bs en 12150 - glass in building. thermally toughened soda lime silicate safety glass. [Online]. Available: https://landingpage.bsigroup.com/ LandingPage/Series?UPI=BS\%20EN\%2012150

[5] A. Khmiri, M. Chaabouni, and B. Samet, "Chemical behaviour of ground waste glass when used as partial cement replacement in mortars," Construction and Building Materials, vol. 44, pp. 74-80, 2013. doi: https://doi.org/10.1016/j.conbuildmat. 2013.02.040

[6] S. Trohalaki, "Soot aggregates from pre-mixed flame observed to have low fractal dimension," MRS Bulletin, vol. 34, no. 9, pp. 627-628, 2009. doi: https://doi.org/10.1557/mrs2009.166

[7] P. Penacho, J. de Brito, and M. R. Veiga, "Physicomechanical and performance characterization of mortars incorporating fine glass waste aggregate," Cement and Concrete Composites, vol. 50, pp. 47-59, 2014. doi: https://doi.org/10.1016/j. cemconcomp.2014.02.007

[8] I. B. Topcu and M. Canbaz, "Properties of concrete containing waste glass," Cement and Concrete Research, vol. 34, no. 2, pp. 267-274, 2004. doi: https://doi.org/10.1016/j.cemconres.2003.07.003

[9] P. Soroushian, M. Elzafraney, A. Nossoni, and H. Chowdhury, "Evaluation of normal-weight and light-weight fillers in extruded cellulose fiber cement products," Cement and Concrete Compos- ites, vol. 28, no. 1, pp. 69-76, 2006. doi: https: //doi.org/10.1016/j.cemconcomp.2004.01.007

[10] G. M. Idorn, "Innovation in concrete researchreview and perspective," Cement and Concrete Research, vol. 35, no. 1, pp. 3-10, 2005. doi: https: //doi.org/10.1016/j.cemconres.2004.09.006

[11] K. Obla, "Variation in concrete strength due to cement," Part III of concrete quality series, Technical services, NRMCA, pp. 1-5, 2010. doi: https: //doi.org/10.1201/b17098-3

[12] J. S. Galsin, "Amorphous solids and liquid crystals," in Solid State Physics. Cambridge, MA: Academic Press, 2019.

[13] S. Kar and M. L. Greenfield, "Sizes and shapes of simulated amorphous cis-and trans-1, 4polybutadiene," Polymer, vol. 62, pp. 129-138, 2015. doi: https://doi.org/10.1016/j.polymer.2015. 01.065

[14] Anon. (2012) Glass in building - basic soda lime silicate glass products - part 1: Definitions and general physical and mechanical properties. [Online]. Available: https://bit.ly/3dWuSOP

[15] M. Testa, O. Malandrino, M. R. Sessa, S. Supino, and D. Sica, "Long-term sustainability from the perspective of cullet recycling in the container glass industry: Evidence from Italy," Sustainability, vol. 9, no. 10, pp. 01-19, 2017. doi: https: //doi.org/10.3390/su9101752

[16] L. C. Malav, K. K. Yadav, N. Gupta, S. Kumar, G. K. Sharma, S. Krishnan, S. Rezania, H. Kamyab, Q. B. Pham, S. Yadav et al., "A review on municipal solid waste as a renewable source for waste-to-energy project in india: Current practices, challenges, and future opportunities," Journal of Cleaner Production, vol. 277, p. 123227, 2020. doi: https://doi.org/10.1016/j.jclepro.2020.123227

[17] Anon. (1962) Chemical resistance of glass used in the production of laboratory glassware. [Online]. Available: https://bit.ly/3yxeAox

[18] B. A. Green and A. Kent, "May class counsel also represent lead plaintiffs?" Fla. L. Rev., vol. 72, p. 1083, 2020. doi: https://doi.org/10.2139/ssrn. 3548872

[19] M. S. Khan, M. Tufail, and M. Mateeullah, "Effects of waste glass powder on the geotechnical properties of loose subsoils," Civil Engineering Journal, vol. 4, no. 9, pp. 2044-2051, 2018. doi: https: //doi.org/10.28991/cej-03091137

[20] T. Drzymała, W. Jackiewicz-Rek, M. Tomaszewski, A. Kuś, J. Gałaj, and R. Šukys, "Effects of high temperature on the properties 
of high performance concrete (HPC)," Procedia Engineering, vol. 172, pp. 256-263, 2017. doi: https://doi.org/10.1016/j.proeng.2017.02.108

[21] A. Dixit, S. Dai Pang, S.-H. Kang, and J. Moon, "Lightweight structural cement composites with expanded polystyrene (EPS) for enhanced thermal insulation," Cement and Concrete Composites, vol. 102, pp. 185-197, 2019. doi: https://doi.org/10. 1016/j.cemconcomp.2019.04.023

[22] Y. Chen, F. Wu, Q. Yu, and H. Brouwers, "Biobased ultra-lightweight concrete applying miscanthus fibers: Acoustic absorption and thermal insulation," Cement and Concrete Composites, vol. 114, p. 103829, 2020. doi: https://doi.org/10.1016/ j.cemconcomp.2020.103829 